Article

\title{
On the Role of External Walls in the Reduction of Energy Demand and the Mitigation of Human Thermal Discomfort
}

\author{
Tomasz Kisilewicz
}

Department of Building and Building Physics, Cracow University of Technology, 31-155 Kraków, Poland; tkisilew@pk.edu.pl; Tel.: +48-126-282-397

Received: 28 December 2018; Accepted: 12 February 2019; Published: 18 February 2019

\begin{abstract}
The structure and thermal properties of external walls affect both the thermal conditions inside the building and the energy demand. This applies to the energy requirement for heating as well as cooling. While the relationship between thermal insulation and heating is well-known, the effect of thermal insulation on overheating is not evident. One can find opinions that thick thermal insulation creates a "thermos effect" and significantly deteriorates the comfort conditions during the summer. In order to prove these statements, an office room with south-oriented glazing and a high thermal load from equipment was simulated by means of the Energy Plus program. The reference variant was a two-layer wall made from ceramic blocks and a $10 \mathrm{~cm}$ layer of thermal insulation. The duration of overheating in the investigated intensively used office space without window shading was approximately 26 to 29 days per year, depending on the expected comfort acceptance range, while in the case of the not insulated wall, it would be shorter by over 3 days. Increasing the thickness of the thermal insulation layer by up to $30 \mathrm{~cm}$ extended the overheating period by $4 \%$ to $9 \%$. In relation to the whole simulation period, covering four summer months, this means approximately two extra days of discomfort. The effects of various passive methods of protecting buildings against overheating were also investigated. The use of night ventilation in this facility enables reducing the unfavorable conditions by as much as $31 \%$, or up to $46 \%$ of the initial period of overheating. The change of the thermal inertia of a building by replacing the ceramic layer with heavy structural concrete allows a further reduction of the overheating duration by $8 \%$ to $9 \%$. When the most effective ways of overheating protection are applied, such as night cooling, even a significant thickening of insulation no longer has any impact on its duration. The results shown above are obviously related to the adopted assumptions. However, on the basis of the conducted analyses, it is possible to reduce concerns relating to excessive insulating the building with respect to overheating. Having an optimal window area with nighttime cooling of buildings, window shading, and the inertial benefits associated with a massive construction are the most important and effective measures of protection against overheating. Efficient thermal insulation of the walls does not conflict with the thermal comfort conditions.
\end{abstract}

Keywords: thermal insulation; overheating; passive cooling; thermal mass; night cooling

\section{Introduction}

The obvious goal of the research related to energy consumption in the sustainable building sector is to minimize the energy demand on heating, thus reducing the carbon footprint, $\mathrm{CO}_{2}$ emission, and smog. However, a less obvious aspect of these activities is the reduction of energy consumption arising from cooling needs. Technological progress, the increased wealth of many societies and, to some 
extent, climate change have made energy-intensive mechanical cooling systems a standard even in the moderate climate zone.

The current European energy directives cover cooling needs; however, it must be stated that the simplest, nonexpensive possibilities to protect the building against the influence of the external environment are not sufficiently used nowadays. Instead of the rational design and adaptation of the building to climatic conditions, the dominant influence of architectural fashion and sometimes controversial aesthetic effects is often followed. So-called passive solutions, that complement the heating system and reduce overheating, have been known for a long time. Many of these solutions have been included in traditional buildings and are usually well adapted to local climate. These solutions only require some knowledge and consistency at the design stage. They can effectively and without any significant extra costs satisfy the need to protect the environment from further degradation, while at the same time, contribute to the protection of human wellbeing. Ibrahim et al. [1] suggested even that in the northern England climate, passive overheating mitigation measures might be sufficient enough to prevent summertime discomfort now and in the future.

The simplest, but unfortunately rarely used overheating prevention measure is ensuring a rational glazing area [2]. The term 'rational' here refers to an optimized glazing area which considers the combined minimization of the energy demand on heating and cooling simultaneously. As usual, it is easier to formulate such a general goal than to implement it in designing practice. The rational glazing area depends on many detailed building solutions and parameters. These include window orientation, glazing transparency and thermal resistance, thermal balance of the space, thermal capacity of the building envelope, openness of the interior and, of course, local climatic conditions [3]. Such a complicated multiparameter function makes it very difficult to formulate simple designing rules. Advanced simulation analyses are required for this purpose. Such simulation analyses, however, are not commonly used by designers. As a result, instead of rational algorithms at the designer's disposal, it is often only the aesthetic criteria or current fashion aspects that remain. In the available literature, the author found only one description of the extended design algorithm used to optimize the window area [4]. In this paper, it was suggested that the standard process of decision making should be reversed. Window sizing, usually performed at the first stage of architectural design, should follow the basic technical decisions. In the climate of central Europe, with its moderate summer air temperature values, one of the basic reasons for overheating is usually an improperly selected area of glazed partitions: this is why it is so important to rationalize this decision.

Another common and simple measure for overheating prevention, which is not considered in this paper, is to block excessive solar gains by means of permanent or temporary window shading, sun breakers, etc. $[1,2,5]$. These obvious solutions, however, are often associated with the consequences of restricted access of daylight. Especially in the case of office or public utility buildings, this may lead to a common paradox: efficient protection against excessive solar gains forces occupants to use artificial lighting and, as a result, to increase energy consumption. However, there are more technically advanced smart solutions which enable the dynamic adjustment of the glazing properties to the current user's needs (thermo- or electrochromic glazing). Absorption of solar radiation on the surface of the opaque envelope should be taken into account and the possibility of lowering its albedo [6].

One more simple measure of space protection against overheating is night cooling, which was often discussed in the reported research. The thermal efficiency of this process is strongly related to the thermal capacity of the given space [7-9]. Evola et al. [10] and Ibrahim et al. [1] emphasized the synergic effect of mass and ventilation. Long-lasting effects depend on the volume and thermal diffusivity of the storing materials [11]. However, in the case of the simplest building solutions and material modifications introduced only to external walls, the expected results may be easily overestimated.

The abovementioned simple solutions and design measures for limiting and preventing the overheating of buildings should all be considered in the building design process. However, no problem has yet been identified with regard to the direct influence of the structure and thermal insulation of the external building envelope on the internal space overheating. 
Thus far, a lot of research has been devoted to the influence of thermal insulation on heating and the hygienic conditions of the building interior. One can also find many articles concerning the optimisation of insulation thickness and the economic aspects of building insulation in the context of heating. Many papers have also been written on the relationship between the external envelope and overheating concern thermal inertia and the manner in which the layers in the external housing are arranged. One of the most classic and frequently cited articles on the method of component design is the paper written by Kossecka and Kośny [12]. The authors conducted the whole building simulation analysis using DOE-2 for six different US climates. The best performance in general (reduction of both heating and cooling load) was obtained when massive layers were located on the inner side of the external component and were in good thermal contact with the space. The total reduction of heating and cooling demand due to the advised 'all insulation outside' layer arrangement may exceed $11 \%$ in a continuously heated building.

Aste et al. [13], in a paper regarding inertia and the thermal performance of well insulated buildings, emphasized the positive influence of high thermal inertia and did not report any conflict between overheating and insulation.

Kośny et al. [14] investigated the influence of thermal insulation enhanced with condensed and dispersed phase changing material (PCM) on the mitigation of cooling load in the loft spaces of residential homes. The addition of PCM increases the thermal capacity of lightweight building technology resulting in a reduction of the cooling load. Condensed PCM fitted in the middle and on the bottom of the loft floor performed better than other arrangements, including PCM dispersed in the whole volume of the insulation. The reduction of insulation thickness was not considered to be an appropriate measure for reducing overheating, although the adopted climate conditions were cooling-dominated. The authors point out the importance of time-shift of peak hour load and reverse heat flow that can be observed in PCM-enhanced components.

Tuohy et al. [15] investigated the influence of thermal mass, insulation, and ventilation on the energy demand of sustainable buildings in the moderate climate of northern Europe using the ESP-r simulation model. They compared three different insulation standards: UK regular, UK advanced, and passive building. The $U$-value of the external building shell in the passive building was very low: $0.1 \mathrm{~W} /\left(\mathrm{m}^{2} \mathrm{~K}\right)$ for wall and roof. The authors did not report any relationship between the cooling energy demand and thermal resistance. More important in the aspect of cooling was thermal mass of the building structure, ventilation, and window shading strategy.

Verbeke et al. [16] delivered a comprehensive review on the role of thermal inertia of building in different climates and occupancy scenarios. In general, building inertia has a positive impact on thermal comfort; however, its relationship with energy demand is more complicated. The cited authors predict a slight reduction of heating-energy use in massive buildings, although conversely, small increases in the energy demand were also reported for intermittently heated buildings in cool climates, dependent upon the insulation level. The authors emphasize not only the necessity to adjust building features (insulation and thermal inertia) to the local climate conditions and building usage, but also the need for dynamic calculations and procedures. They also consider various arrangements of insulation, massive materials, and various ventilation schemes. The broad review of the articles did not result in any predominant conclusions that would be easy to adopt in any building and climate. The authors suggest that each case should be considered separately because, even for a given building type, many parameters, such as the occupancy patterns, glazed surface, and thermal insulation, have a significant impact. Verbeke et al. [16], in their review, found that in some cases-especially concerning nonresidential buildings in a warm climate-high thermal inertia resulted in an increased cooling demand, but evidence suggested that proper (nighttime) ventilation strategies could overcome this.

Despite the abovementioned studies, there remains little information about the direct relationship between thermal insulation of the building envelope and the overheating of the interior space. The common opinion is that thermal insulation of the external envelope in hot summer conditions 
inhibits the discharge of heat to the external environment and thus significantly increases overheating intensity $[7,10,11]$.

Stazi [11] wrote that a 'hyperinsulated' envelope is an efficient barrier in the dissipation of heat to the external environment. Despite emphasizing the necessity to block incoming heat waves by means of capacitive and resistive wall layers, she criticized the use of very thick insulation layers that attenuate heat flow intensity too much. In her opinion, the new solutions create a thermos effect that prevents outgoing heat flux, especially during the hot and intermediate seasons. Her research is mostly concentrated on a warm (Italian) climate, but the last statement is also addressed to cold climate conditions. Overheating risk was in [11] confronted with present European energy saving standards. Especially in case of passive or zero-energy buildings, required high thermal resistance and overheating prevention are in a distinct conflict. To solve this issue in Italian conditions Stazi proposed a dynamic insulation system, which is open in summer and sealed in winter.

In fact, the rationality of this kind of approach is not evident and has not been proven by any available and comprehensive analysis of external wall heat balance. In summer, insulation enables protection of the space against the absorbed solar heat and the heat wave induced by the rapid rise of external air temperature during a hot day. The daily dynamic balance of the massive and well insulated wall is completely different than in a simple stationary approach and, in fact, there is no conflict between the reduction of energy consumption and overheating protection.

Fanga et al. [17] conducted measurements in two experimental free standing chambers in hot climate conditions. One of these was a traditional structure without insulation and the second was modernized and insulated. The results of testing proved that the insulated chamber was less affected (lower demand on cooling) by the external heat waves and absorbed solar radiation and maintained better thermal conditions than the traditional structure. Average heat flux intensity through the wall was at least two times lower in the insulated chamber than in the uninsulated chamber.

Yuan et al. [18] tested the influence of insulation on thermal comfort in an intermittently air conditioned office building in China. They found out that in this special case, the internal location of insulation is more advantageous due to the rapid reaction to air temperature changes. The high thermal resistance of insulation did not change the results. The presence of insulation was most significant in the case of the south-oriented wall.

Al-Sanea et al. [19] reported a decreasing cooling energy load with increases to thermal resistance in the Saud Arabian climate.

Kolaitis et al. [20] conducted a comparative assessment of internal and external insulation systems used for the retrofitting of residential buildings in a warm south European climate. An apartment located at the mid-level of a multistory building was simulated in the TRNSYS software. Both insulation systems significantly reduced the total energy demand; the rate of reduction depended on local climate and occupant behavior. In the case of the cooling demand only, the application of thermal insulation may result in a higher energy demand. The actual result depends on building usage. Active occupancy, such as window shading or night ventilation, may compensate for this effect and result in a final reduction of the cooling demand. The thermal efficiency of the external insulation system was $8 \%$ higher than that of internal system.

Most of the papers reported above relate to warm or even hot climate conditions. Goia et al. [21] investigated the significance of thermal inertia in the cold Norwegian climate. The subject of simulation was a theoretical opaque wall that did not incorporate any existing technology and was made form one homogenous layer. Its energetic features were represented by steady state thermal transmittance $U$ and dynamic thermal transmittance $Y_{i e}$. These two parameters were considered as independent variables. This study revealed that there is a poor relationship between heating, cooling and thermal inertia in such conditions, especially in the case of well insulated buildings. The most important factor is the steady state thermal transmittance of the external envelope. Goia et al. also observed that a reduction of the $U$-value to below $0.1-0.15 \mathrm{~W} /\left(\mathrm{m}^{2} \mathrm{~K}\right)$ in a building equipped with a cooling system 
resulted in higher total energy consumption than in the case of less insulated buildings. The number of overheating hours in a building without a cooling system increases with wall thermal resistance.

Kisilewicz [22], in his report on measurements, announced that during a hot and sunny week more energy was delivered to the space than was transferred through the insulated south-oriented wall to the external environment. In spite of the recorded large environmental temperature differences, there was no evident effect of surplus energy discharge to the external environment during this week.

The articles quoted above present contradictory views. The influence of thermal insulation on decreasing overheating is positively evaluated in some cases, but there are also completely opposing opinions. Authors do not usually deal with the thermal balance of building external envelope; rather their conclusions are based on the results of tests or simulations for entire rooms. A large number of interconnected parameters parameters can cause the final conclusions to be dependent upon the specifics of individual cases. In addition, there is also the problem of the sensitivity of results to climatic conditions. Therefore, the main purpose of this article is to assess the relationship between the thermal resistance of the external wall and the overheating of the space in the conditions of the central European climate. Solving this problem is of great practical importance in the design of low-energy buildings.

\section{Materials and Methods}

\subsection{Dynamic Thermal Characteristics}

The commonly used simple relationships describing the thermal properties of buildings are based on a stationary description of heat flow. However, the conditions that take place during hot days have a strongly dynamic character.

One of the simplest and best known dynamic models of heat transfer is a theory of harmonic heat waves, based on a Fourier analysis of cyclic functions. Due to a quasi-periodic course of ambient temperature and the Fourier analysis tool, this analytical approach allows accurate modelling of real conditions [9]. In International Standard EN ISO 13786 [23], only sinusoidal boundary conditions are considered: building boundaries are submitted to sinusoidal variations of temperature or heat flow rate.

Thermal admittance $Y$ (in the form of a complex number) relates the heat flow rate to temperature variations on the same side of the component. Transmittance is a complex quantity defined as the amplitude of the density of heat flow rate through the surface of the component adjacent to zone $m$, divided by the amplitude of the temperature in zone $n$ when the temperature in zone $m$ is held constant.

In European standard EN ISO 13792, a periodic approach called Admittance Procedure is recommended as a simplified method for the calculation of air temperature in a space without mechanical cooling.

The combined thermal characteristics of the component under steady and periodic conditions may be expressed as a decrement factor $f$, i.e., the ratio of the modulus of the periodic thermal transmittance to the value of the steady-state thermal transmittance $U$.

Periodic thermal transmittance is responsible for the propagation of sinusoidal thermal waves across the building component. External environment variations occur not only as a the result of ambient temperature changes but also as a result of solar radiation absorbed by the external surface of a building shell. Low transmittance on the one hand may prevent internal heat dissipation, but on the other hand, it protects space against the conduction of absorbed solar energy. A large phase shift is an important aspect of heat transfer, which allows the separation in time of solar gains through the windows and gains due to the conducted heat wave [9]. Shifted in time energy flux may be efficiently removed by intensive night ventilation.

The harmonic heat flow model, based on analytical physical equations, was devised a long time ago. Due to computational problems, it was initially used in a simplified form; however, nowadays the use of a computer enables the rapid execution of the full calculation procedure. The most important whole building simulation programs currently use other numerical methods of analysis, but the 
harmonic model is still widely used, not only in the designing process for the dynamic characteristics of building components but even for the whole space analysis. The dynamic quantities presented above enable the characterization and comparison of building elements in terms of their response to changing environmental conditions.

In her work [11], Stazi adopted the decrement factor and the areal thermal capacity as the main dynamic parameters. She introduced and recommended the ranges of these parameters for a low energy building envelope.

A similar approach was presented by Aste et al. [13]. The authors characterized the building elements' inertia by dynamic thermal transmittance and internal thermal admittance, and treated them as a necessary base for rational design decisions. In a simplified approach building mass is sometimes identified as a sufficient indicator of thermal inertia. Aste et al. [13] proved that this is an inappropriate approach and the more advanced dynamic measures are necessary.

Gori et al. [24] formulated a design criterion for effectively insulated structure that was based on two dynamic features: decrement factor and time delay. The subject of their research also covered the method of dividing the wall layers into smaller parts and their proper arrangement in order to obtain optimal insulating properties. Only advanced analyses of this type enable building designers to evaluate the dynamic properties of the partitions and to control expected features. Gori et al. [24] showed that under specific circumstances, the optimum number of layers can be identified.

Di Perna et al. [25] assessed the influence of thermal mass on summertime thermal comfort in buildings with high internal heat loads. They have determined the threshold values of the areal capacity with respect to the dynamic transmittance of the wall by using the adaptive thermal comfort approach. According to the proposed threshold values, the higher the dynamic thermal transmittance of the wall, the higher the internal thermal capacity. The authors suggested use of the obtained results in mandatory regulations regarding low energy design.

A particularly thorough analysis of dynamic properties was performed by Kossecka et al. [12]. The authors presented all the dynamic characteristics of the external building component and calculated them for six different patterns of mass distribution and insulation of the external wall. Dynamic internal admittance was highlighted as the most prominent factor of thermal comfort.

A similar problem was considered by Al-Sanea et al. [19] in the warm climate conditions of Rijad. The authors considered optimum thermal resistance and analyzed the effect of thermal mass distribution, comparing values of the decrement factor, time lag, and thermal transmittance.

Goia et al. [21] compared the practical significance of steady state and dynamic transmittances in cold climate conditions. They found dynamic thermal transmittance to be insignificant for the heating and cooling demand. Unfortunately, the authors did not consider the influence of internal admittance in a highly glazed building.

Verbeke et al. [16] covered all dynamic thermal characteristics in a comprehensive literature review of 179 papers on thermal inertia.

In light of this brief literature review, it should be noted that the periodic model of dynamic phenomena in buildings is widespread and readily used. As shown by the cited authors, it is not possible to fully characterize building partitions without a set of dynamic quantities. Contemporary design of the building envelope requires advanced tools that accurately assess the correctness of the selection of materials, layer thicknesses, and their spatial arrangement in the partition.

In further research work, thermal transmittance $Y$ and decrement factor $f$ were used as a concise description of the dynamic wall characteristics; $D^{\prime}$ Thermal software was used to calculate these values. The basic material features of the analyzed wall structure are presented in Table 1.

The same wall structure as above was tested in an office building under summer conditions [26]. This type of wall was adopted in further analyses as a reference variant. The standard dynamic characteristics of the wall were calculated and the results of the calculation are compiled in Table 2. This analysis was conducted in accordance with standard [23] over a period of $24 \mathrm{~h}$. 
Table 1. Reference wall structure *.

\begin{tabular}{|c|c|c|c|c|}
\hline & $\begin{array}{c}\text { Thicknessd } \\
\text { (m) }\end{array}$ & $\begin{array}{l}\text { Density } \rho \\
\left(\mathrm{kg} / \mathrm{m}^{3}\right)\end{array}$ & $\begin{array}{c}\text { Thermal Conductivity } \\
\lambda(\mathrm{W} /(\mathrm{m} \cdot \mathrm{K}))\end{array}$ & $\begin{array}{l}\text { Specific Heat c } \\
(\mathrm{J} /(\mathrm{kg} \cdot \mathrm{K}))\end{array}$ \\
\hline internal plaster & 0.02 & 1700 & 0.8 & 840 \\
\hline ceramic blocs & 0.188 & 800 & 0.21 & 880 \\
\hline exp. polystyrene & 0.1 & 10 & 0.045 & 1460 \\
\hline external plaster & 0.01 & 2000 & 1.0 & 840 \\
\hline
\end{tabular}

* The data in Table 1 was partially taken from standard PN-EN 12524:2003 and the data sheet delivered by the Polish Building Research Institute.

Table 2. Dynamic characteristics of the analyzed wall over a $24 \mathrm{~h}$ period (surface thermal resistances excluded).

\begin{tabular}{ccc}
\hline & Modulus $\left(\mathbf{W} /\left(\mathbf{m}^{\mathbf{2}} \mathbf{K}\right)\right)$ & Time Lead/Shift $\mathbf{( h )}$ \\
\hline external admittance & 1.357 & 4.811 \\
internal admittance & 4.726 & 3.859 \\
transmittance & 0.096 & -8.136 \\
\hline
\end{tabular}

The calculations were performed using complex numbers consisting of both real and imaginary components. The result of the calculation in the form of a complex number enables calculating the value of the module of this number and the phase shift expressed in hours. These two pieces of information already have an easy-to-interpret physical meaning. The structural layer of the wall made of ceramic blocks has a relatively low level of thermal conductivity: in combination with a thermal insulation layer, this results in a low internal admittance module $\left(4.726 \mathrm{~W} /\left(\mathrm{m}^{2} \mathrm{~K}\right)\right)$ and a very low transmittance module $\left(0.096 \mathrm{~W} /\left(\mathrm{m}^{2} \cdot \mathrm{K}\right)\right)$. Time shift of transmittance is information about time difference between temperature wave on one side and resulting heat flux on the other side. A large shift is advantageous due to cooling possibilities during the night.

The calculated internal areal heat capacity of the wall (without surface resistances) is moderate and equal to $66.316 \mathrm{~kJ} / \mathrm{m}^{2} \mathrm{~K}$, while a very low external areal heat capacity is $19.951 \mathrm{~kJ} /\left(\mathrm{m}^{2} \mathrm{~K}\right)$. The decrement factor is 0.220 .

\subsection{Computer Simulation Model}

Because of the complexity of heat exchange and dynamic heat flow in the building shell, every building is practically a unique system and therefore it does not conform to simple formulas or stationary calculations. Awareness of this fact results in the regular use of computer simulation programs or at least the development of special tools and procedures for those who are concerned with thermal comfort in designed objects.

One of the few comprehensive tools of this type is Energy Plus, which is still being developed, modified, and extended with new modules by the U.S. Department of Energy, the National Renewable Energy Laboratory, and the other cooperating institutions. The Energy Plus program has repeatedly been experimentally validated by various researchers worldwide, but the main validation studies were conducted by the US governmental agencies that finance the program. One of the exemplary validation reports was delivered by Henninger [27].

As a reference object of simulation in the Energy Plus program, a southeast corner space was chosen which is a part of a symmetrical building story, Figure 1. An external facade is rather more typical for residential buildings than it is for modern office buildings with oversized glazing area. The same wall, that was analyzed above in dynamic conditions will be used in computer simulation in order to investigate and better understand the role of the external wall structure of the building in a dynamic heat transfer process.

The whole floor was divided into five parts which were simulated as separate thermal zones. The southern zone of the building has the greatest potential for solar energy gains to support the heating system during the winter. However, the risk of overheating during summer or even during 
transitional periods is considerably greater in this zone than in the case of any other parts of the building. This is why only simulation results for the southeast zone will be discussed further, Figure 1 . The floor area of Zone V is $20 \mathrm{~m}^{2}$ and the ratio of the south glazing area to the floor area is equal to $17.2 \%$.

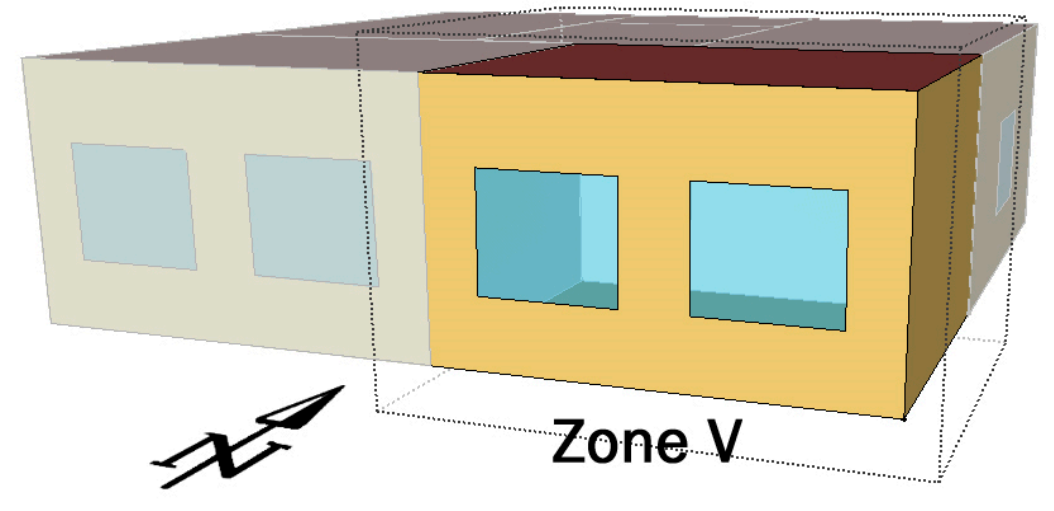

Figure 1. Simulated object with southeast corner space.

A relatively small office room $(4 \times 5 \mathrm{~m})$ was used for the analysis. The aim of the paper is to assess the impact of the external building envelope on indoor conditions. In a small separated room, this impact is significant; however, in open space of a large-sized office building, one can expect that the influence of the external wall will be unnoticeable. In a hot summer period, the influence of the elevated radiant temperature of the external wall can have a particularly large impact in such a room. Office spaces are associated with high internal thermal gains, which create additional unfavorable conditions in the interior. The combination of both factors therefore places special requirements on the designer. It could be also expected that the results obtained for the unfavorable office conditions can be easily transferred to less demanding - in the sense of thermal load-living spaces. According to the European Standard EN ISO 15251:2012 [27], the adaptive comfort criteria may be extended to apartment buildings under the same conditions as for offices.

The building was simulated in the summer period (May 1-September 30, in total $3672 \mathrm{~h}$ ), but most attention was paid to the hottest week in July.

In the reference case, the air change rate in the simulated zone is $5 \mathrm{~h}^{-1}$ during office working hours (07:00-17:00) due to opened windows and exhaust fans, and only $0.5 \mathrm{~h}^{-1}$ during the night (windows closed). This is not a rational way of building operation during hot periods, but unfortunately, it is commonly applied because of safety reasons, protection against wind, driving rain, etc. To minimize diurnal overheating, ventilation in the simulated building is automatically shut off when the temperature difference between the analyzed zone and the ambient air is lower than $1 \mathrm{~K}$. It was also assumed that the indoor air temperature in an office building cannot fall below $20{ }^{\circ} \mathrm{C}$ at night during the summer period in order to avoid thermal discomfort the following morning. There is no air exchange between the separate thermal zones of this building.

In the analyzed room CFD analysis was not conducted, thus neither the air change intensity nor the local air velocity values were calculated. Under the conditions of natural air exchange, resulting mainly from the opening of windows and depending on the thermal conditions and the direction and speed of the wind, the variability of the indoor conditions is enormous. However, this is a situation which is compliant with the assumptions of the adaptive comfort model in which the user has a certain ability to control the conditions in the room. The air exchange values given above are therefore the computational assumptions. At night, in the reference variant, the air exchange responds to air infiltration through closed windows.

In the modeled room air is not conditioned-indoor air humidity results directly from ambient conditions. Taking into account intensive air exchange during the day, it was assumed that the impact of office users is insignificant. The average relative humidity of the outside air in the climate of central 
Poland is 75 to $77 \%$ in the summer months and, due to higher internal air temperature, the average internal humidity is 60 to $65 \%$ in these conditions. According to the requirements of the Standard EN ISO 15251:2012 [27] and the adaptive thermal comfort model, relative humidity is not considered in this approach.

The following heat gain sources are present in the analyzed part of the building.

- Three people working since 08:00 until 17:00, wearing light clothes, and engaging in sedentary activity.

- Room lighting and heat gains from typical office equipment, estimated as $200 \mathrm{~W}$ per person.

The external walls in the reference building are made of ceramic blocs, expanded polystyrene as thermal insulation and plaster. Windows are double-glazed with glazing with a thermal transmittance of $U_{g}$ equal to $1.349 \mathrm{~W} /\left(\mathrm{m}^{2} \mathrm{~K}\right)$. The analyzed space belongs to the middle story of the multistory building; therefore, the separating floors are simulated as the adiabatic planes.

The adopted method of internal microclimate assessment is the adaptive thermal comfort criterion according to ASHRAE Standard 55-2013 [28-30]. The microclimate rating associated with adaptive comfort is based on the gradual adaptation of building user to high temperature conditions in buildings without mechanical cooling which is observed in practice. Due to the natural adaptation mechanism, too high a temperature in a cool season could be regarded as acceptable during the hot season of the year. The degree of adaptation is strictly associated with the user's ability to modify the internal environment, for example, by opening or shading windows, using fans or even forced ventilation, making appropriate clothing choices, etc. [29]. Such measures are available in the simulated building but are not considered in detail in the conducted simulations.

The approach used in the ASHRAE method is very similar to the solution adopted in European Standard EN ISO 15251:2012 [27]. The requirements of the ASHRAE standard for $90 \%$ acceptability limits are slightly more restrictive than those of the first comfort category in the European standard. Various types of overheating dynamic and static indices were widely discussed by Psomas et al. [31], but no commonly applied relationship was developed.

Discomfort duration based on the adaptive thermal comfort criterion is used in this paper as the main tool of comparison and evaluation of the analyzed options. An important practical advantage of using this approach in the Energy Plus simulations is the fact that this program comes with the option of discomfort duration count, i.e., the number of hours with internal operative temperature beyond the adaptive comfort range for two user acceptance levels: $90 \%$ and $80 \%$.

\section{Results}

\subsection{Reference Object-Results of Simulation}

The accumulated thermal comfort results obtained for the reference case of the simulated object (external wall made of ceramic blocs and $10 \mathrm{~cm}$ of expanded polystyrene EPS) are presented below.

\begin{tabular}{ccc}
\hline Acceptance range & $90 \%$ & $80 \%$ \\
\hline discomfort duration $(\mathrm{h})$ & 699 & 620 \\
\hline
\end{tabular}

For the two considered acceptance levels, the number of hours during which the internal thermal conditions are beyond the adaptive comfort range (discomfort duration) are provided.

Intolerable overheating covers $19 \%$ and $17 \%$ of the whole simulated period for the $90 \%$ and $80 \%$ acceptance ranges, respectively.

It may be expected that the very high number of discomfort hours in the southern zone is mostly the result of large solar gains through windows with high solar radiation transmittance (transmission factor $g=0.724)$. However, the real structure of energy balance is in this case different to that which was expected, Figure 2 . The biggest fraction of the heat load (41\%) is due to internal gains, and solar 
gains account for $36 \%$ of the total space load. This structure of thermal gains is in part the result of the adopted building model with a moderate window area. The proportion of solar and internal gains in a modern glass building would be significantly different.
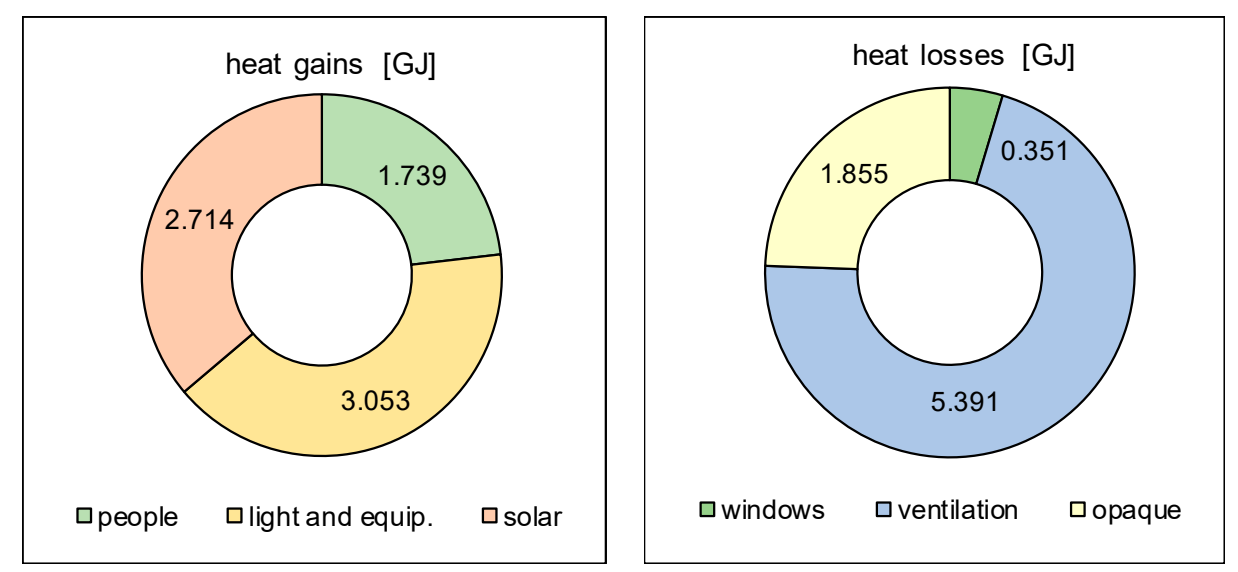

Figure 2. The structure of energy gains (left) and energy losses (right).

When it comes to energy losses, heat transfer via the opaque building shell is a relatively small fraction ( $24 \%$ of the heat dissipated to external environment) while the heat exchange by ventilation is $71 \%$.

It was assumed that a right measure of thermal sensible conditions in the building is the operative temperature, i.e., the weighted mean of air temperature in the simulated space and average radiant temperature of the building components. A chart of the operative temperature in the simulated office space and the external air temperature for the chosen hot July week is presented in Figure 3.

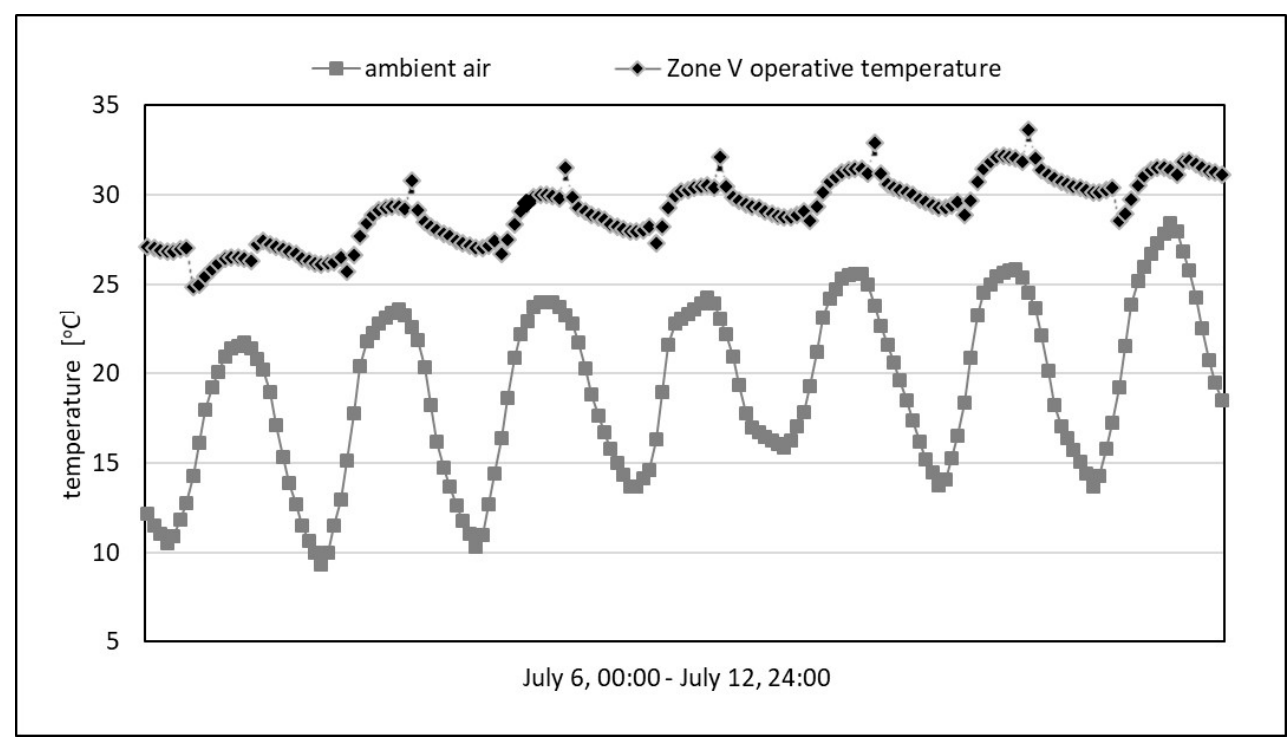

Figure 3. External air temperature and internal operative temperature in Zone V; reference building with air change rate equal to $5 \mathrm{~h}^{-1}$ during working hours (07:00-17:00) and $0.5 \mathrm{~h}^{-1}$ during the night.

The simulated office space was intensively overheated during the analyzed period. A temperature of $27^{\circ} \mathrm{C}$ is usually regarded as the maximum temperature at which people can still work. It is associated with a significant thermal load on the human body; such conditions are located far beyond the thermal comfort area. In the analyzed building space, the operative temperature goes much higher than this value, reaching a maximum of $32^{\circ} \mathrm{C}$, i.e., unbearable thermal conditions. However, at each moment of this week, even during the hottest day, there was still a large potential for space cooling by 
more intensive air exchange. During the night, the momentary temperature difference between the building interior and the ambient air was even greater than $15 \mathrm{~K}$, but the opportunity to cool down the space was not taken due to the closed windows and air exchange reduced to infiltration $\left(0.5 \mathrm{~h}^{-1}\right)$.

\subsection{Noninsulated External Wall}

The accumulated thermal comfort results with regard to discomfort duration obtained for the noninsulated external wall are as follows.

\begin{tabular}{ccc}
\hline Acceptance range & $90 \%$ & $80 \%$ \\
\hline discomfort duration $(\mathrm{h})$ & 620 & 539 \\
\hline
\end{tabular}

Overheating time covers $17 \%$ and $15 \%$ of the whole simulated period for the $90 \%$ and $80 \%$ acceptance ranges, respectively. Both numbers are slightly reduced when compared to the reference case with the standard wall resistance, but also in this case, overheating intensity is significant. In the analyzed case and the adopted climate conditions, the thermal insulation barrier contributes only to a small increase of overheating intensity during the hot summer period.

In order to confirm the role of thermal insulation, the internal operative temperature in Zone $\mathrm{V}$ during one hot summer day is shown below for the reference building and a theoretical case without thermal insulation, see Figure 4.

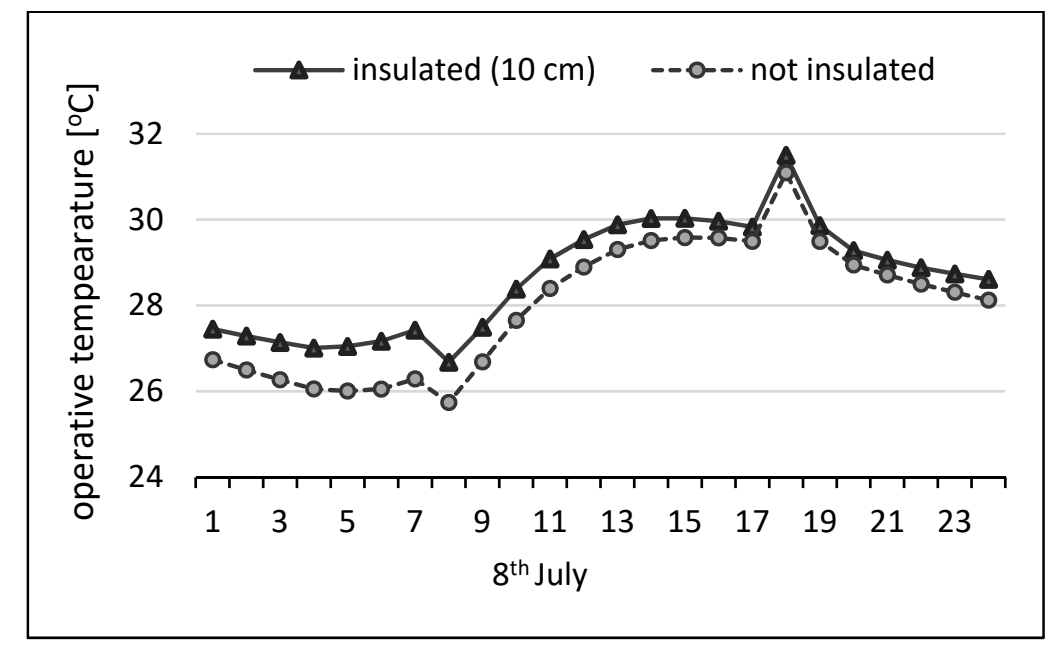

Figure 4. Operative temperature in Zone V with reference external wall and noninsulated wall, 8th July.

As could be expected, in the case of the chosen hot day and the assumed building operation mode, operative temperature is constantly higher in the insulated building. Total daily difference is equal to 15.43 degree hours. However, it should be emphasized that a lack of insulation does not ensure thermal comfort in this space. Conductive heat transfer is not enough to discharge the collected energy. The irregular shape of the curves is the result of abrupt changes of ventilation intensity at 07:00 and 17:00.

In Figure 5, the diurnal fluctuations of the so-called 'average face conduction heat transfer across external wall' (Energy Plus Input Output Documentation) are shown for the reference and noninsulated building. The average face conduction heat transfer combines inside face conduction and outside face conduction in Energy Plus and is simply equal to the average of these two values. According to the adopted sign convention, positive values indicate resultant heat flowing towards the internal space. 


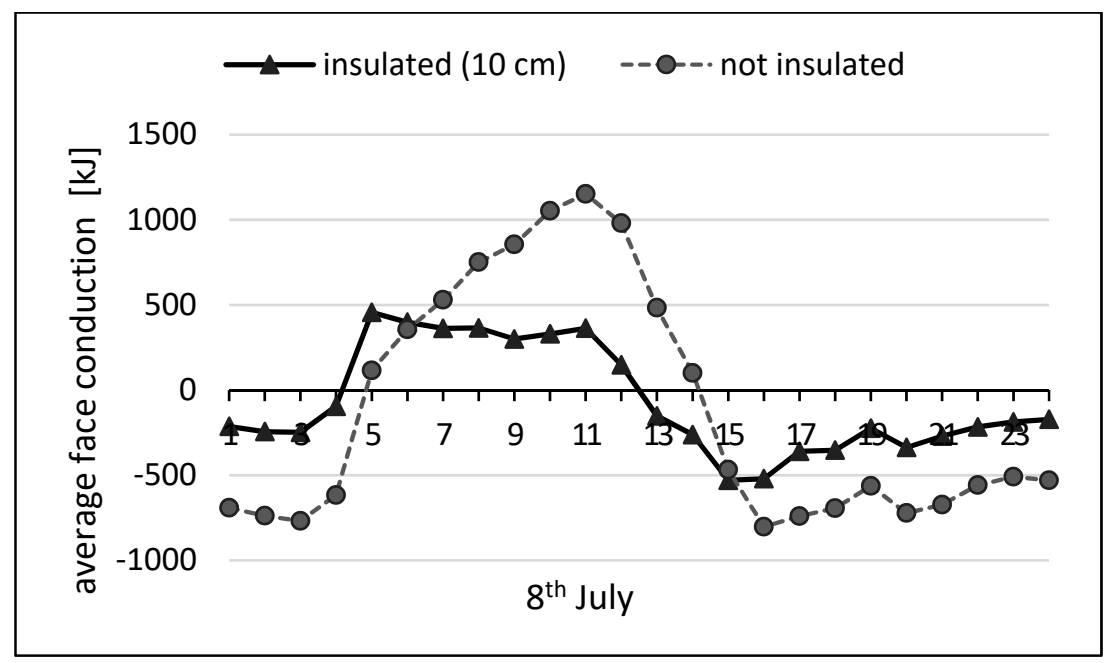

Figure 5. Average (internal and external) face conduction heat transfer for the insulated and noninsulated wall on 8th July.

During the afternoon and night hours, the average face conduction heat transfer is negative for both walls, i.e., more energy is released to the surrounding environment than is delivered to the space. During the daytime, this relationship is reversed. In the case of the insulated wall, the absolute values of heat transfer are usually lower than in the case of noninsulated wall due to the external thermal barrier. However, the resultant diurnal heat transfer is equal to $-1667 \mathrm{~kJ}$ for insulated wall and $-2708 \mathrm{~kJ}$ for not insulated. It means that noninsulated building, on 8 th July, dissipated more energy than the insulated building, even when solar energy is considered. Solar energy absorbed by the external face was partially conducted into the wall and the rest was returned to the external environment. This relationship is sensitive to the wall orientation and in each case, it should be considered separately. In this paper, only the south-oriented walls have been taken into account.

When the calculations are extended to the whole week (July 6-12) the previously reported relationships are maintained, i.e., the weekly balance of the average conducted energy is negative and more energy is dissipated by noninsulated building than by insulated one.

\subsection{Highly Insulated External Wall}

It should be noted that the above-considered case of a massive wall without thermal insulation is definitely a theoretical issue only. It is obvious that the advantage during the hot summer period would not counterbalance energy losses during the rest of the year. Therefore, the practical question is to what extent would a very thick insulation layer, which is required in zero-energy buildings, deteriorate the internal microclimate in summer?

In order to answer this question, a highly insulated building with $30 \mathrm{~cm}$ of efficient insulating material has been simulated. The other features of the building, its operation mode, and the simulation period are exactly the same as for the reference case.

\begin{tabular}{ccc}
\hline Acceptance range & $90 \%$ & $80 \%$ \\
\hline discomfort duration $(\mathrm{h})$ & 730 & 674 \\
\hline
\end{tabular}

In this case, the overheating time, shown above, is slightly longer than in the reference case and covers $20 \%$ and $18 \%$ of the whole simulated period for the $90 \%$ and $80 \%$ acceptance ranges, respectively. These results on one hand confirm prior observations regarding the effect of an insulating barrier, but on the other hand, negate popular and often repeated statements about 'building thermos' or 'excessively insulated buildings'. Figure 6 shows the very limited influence of the increased insulation on the internal microclimate. 


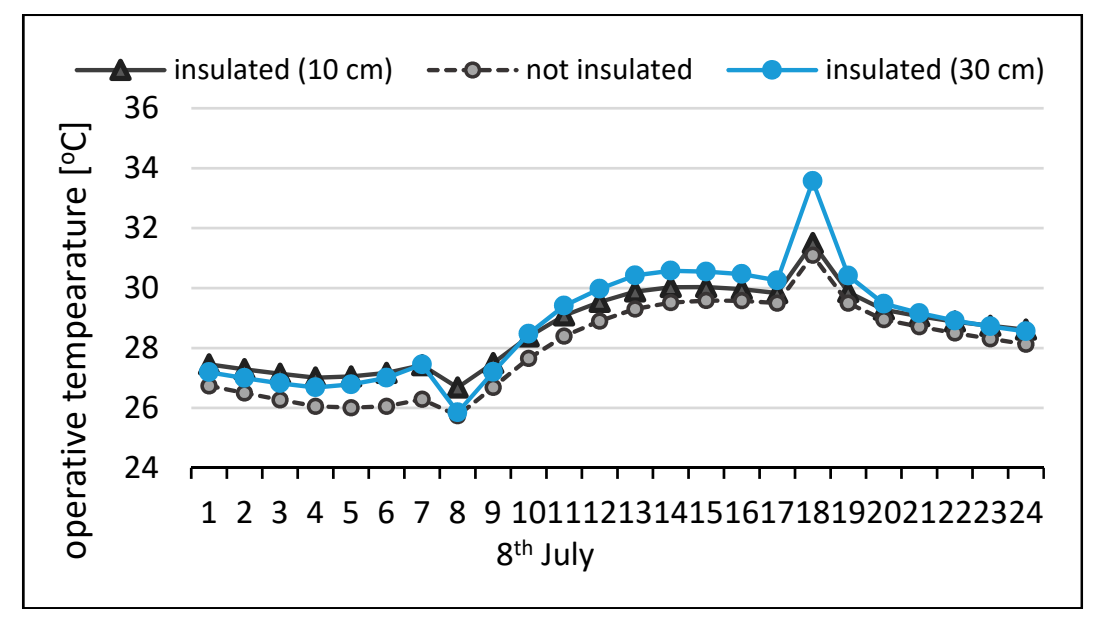

Figure 6. Operative temperature in Zone V with the highly insulated wall $(30 \mathrm{~cm}$ insulation), the reference wall (10 cm insulation) and the noninsulated wall, 8 th July.

Over the course of $11 \mathrm{~h}$, the operative temperature in the highly insulated building is slightly higher than in the reference building and total difference is equal to 3.6 degree hours. In this context, the design decision regarding insulation thickness and its role in space overheating seems to be clear: increased thermal resistance of the external shell of the building does not noticeably deteriorate the internal microclimate during hot periods.

\subsection{Night Cooling and Enhanced Thermal Capacity}

It is evident that other measures should be taken to reduce the space overheating intensity and its duration. The most obvious of these, window shading, is not considered here.

The other easily available measure (night cooling) is well-known, very intuitive, and a widely used cooling method $[1,9,10,22,31]$. However, the effectiveness of this method is strongly related to the dynamic properties of the building components. Initially, night cooling was applied to the reference wall building structure (external wall: ceramic bloc $+10 \mathrm{~cm}$ of thermal insulation).

It was assumed that the air exchange rate was constant at $5 \mathrm{~h}^{-1}$ for each day and night. Alonso et al. [32] proved that exhaust ventilation is the best strategy for summer. Simulation results of this case are presented in Figure 7.

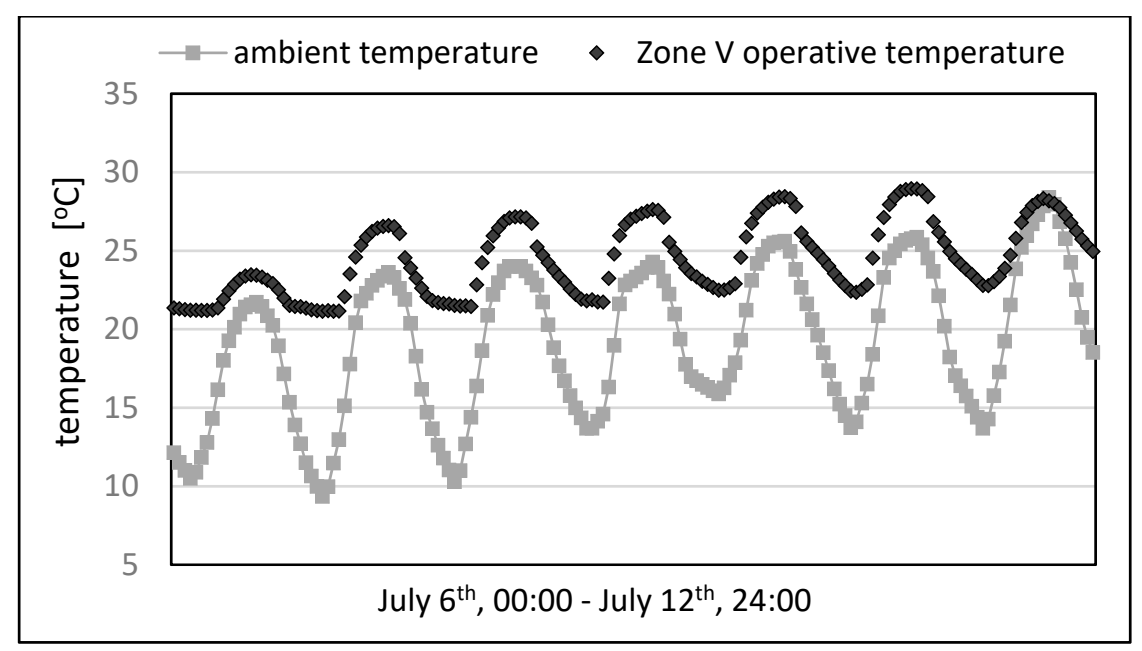

Figure 7. External air temperature versus internal operative temperature in Zone V; reference building with the constant air change rate equal to $5 \mathrm{~h}^{-1}$. 
Much more intensive ventilation in the night resulted in a significant reduction of operative temperature in analyzed zone when compared to the reference case, Figure 3 . In this case, the highest daily temperature is close to $28^{\circ} \mathrm{C}$ and the lowest temperature in this period is $21^{\circ} \mathrm{C}$; in the reference case it was $25{ }^{\circ} \mathrm{C}$. It should be emphasized that a very strict condition was imposed on the night cooling process in the form of a minimum acceptable air temperature equal to $20^{\circ} \mathrm{C}$. Lower minimum temperature during the night would result in a further decrease in the daily maximum temperature.

Substantial improvement of the internal microclimate can be observed when adaptive comfort data are considered.

\begin{tabular}{ccc}
\hline Acceptance range & $90 \%$ & $80 \%$ \\
\hline discomfort duration $(\mathrm{h})$ & 480 & 332 \\
\hline
\end{tabular}

Night cooling enabled shortening of the overheating period by $31 \%$ in the case of the demanded high acceptance range and even by $46 \%$ in the case of the lower acceptance range.

In the simulated building, the main structural layer of the external wall was made of ceramic blocks. Due to the limited thermal conductivity and the medium density of ceramic blocks, internal thermal admittance of the reference wall was $4.726 \mathrm{~W} /\left(\mathrm{m}^{2} \mathrm{~K}\right)$, Table 2. A much higher internal admittance is expected when ceramic blocks are substituted with a reinforced-concrete structural layer of the same thickness. Reinforced-concrete density was $2300 \mathrm{~kg} / \mathrm{m}^{3}$, thermal conductivity was $2.3 \mathrm{~W} /(\mathrm{mK})$, and specific heat was $1000 \mathrm{~J} /(\mathrm{kgK})$. Dynamic characteristics of the wall with the standard insulation $(10 \mathrm{~cm})$ and the concrete structural layer are presented in Table 3.

Table 3. Dynamic characteristics of the high-capacity wall $-24 \mathrm{~h}$ period (surface thermal resistances excluded).

\begin{tabular}{|c|c|c|}
\hline & Modulus $\mathrm{W} /\left(\mathrm{m}^{2} \mathrm{~K}\right)$ & Phase Shift h \\
\hline external admittance & 1.336 & 4.699 \\
\hline internal admittance & 17.020 & 2.567 \\
\hline transmittance & 0.214 & -5.454 \\
\hline
\end{tabular}

External admittance is practically the same as before (Table 2), however, the modulus of internal admittance $\left(17.02 \mathrm{~W} /\left(\mathrm{m}^{2} \mathrm{~K}\right)\right)$ and the internal areal heat capacity $\left(235.53 \mathrm{~kJ} /\left(\mathrm{m}^{2} \mathrm{~K}\right)\right)$ are 3.6 times higher than in the case of ceramic blocks. The transmittance modulus value is increased due to the high conductivity of the reinforced concrete, while the decrement factor value is significantly reduced to 0.172. Such a wall arrangement is a common solution nowadays, especially in high-rise buildings. The discomfort duration data for this case is as follows.

\begin{tabular}{ccc}
\hline Acceptance range & $90 \%$ & $80 \%$ \\
\hline discomfort duration $(\mathrm{h})$ & 436 & 305 \\
\hline
\end{tabular}

This modification of the wall structure had a positive impact on overheating reduction $(9 \%$ and $8 \%$ reduction of overheating time in comparison to ceramic blocks). However, the above improvement would not justify the exchange of the structural materials. When a heavy material is used because of structural or economic reasons it should be regarded as a fully justified and recommended solution.

The last tested variant was the building model with the external superinsulated ( $30 \mathrm{~cm}$ of EPS) massive wall and intensive night cooling. A significant change in the thickness of the thermal insulation, which is a material of low density and low thermal capacity, does not significantly change all the dynamic properties of the partition. In comparison to the previous variant, the damping decrement value decreased from 0.172 to 0.159 . A substantial difference can be observed in the case of the transmittance modulus, from $0.214 \mathrm{~W} /\left(\mathrm{m}^{2} \mathrm{~K}\right)$ to $0.071 \mathrm{~W} /\left(\mathrm{m}^{2} \mathrm{~K}\right)$, and of course in stationary transmittance $U$ from $0.301 \mathrm{~W} /\left(\mathrm{m}^{2} \mathrm{~K}\right)$ to $0.144 \mathrm{~W} /\left(\mathrm{m}^{2} \mathrm{~K}\right)$. Results for the enhanced insulation case are as follows. 


\begin{tabular}{ccc}
\hline Acceptance range & $90 \%$ & $80 \%$ \\
\hline discomfort duration $(\mathrm{h})$ & 442 & 299 \\
\hline
\end{tabular}

The results obtained for this variant confirmed once more that the practical influence of insulation thermal resistance on summer comfort is negligible. In the case of the lower acceptance range, discomfort duration in the highly insulated space is even shorter than in the reference space. However, the observed opposite differences of discomfort duration are quite small $(1 \%$ and $2 \%$ for the $90 \%$ and $80 \%$ acceptance ranges, respectively, when compared to standard insulation) and may be the result of the limited accuracy of calculations.

\section{Discussion}

One of the important sustainable design tasks is to use the simplest, passive possibilities to protect the building against overheating $[1,11]$. The protection methods should be adapted to the current needs and the individual structure of the heat balance of the considered building [32]. The simplest measure, but unfortunately rarely used, is rational glazing area. A short discussion of this issue was included in introduction. A rational window area, optimized to heating and overheating criteria, reduces the heat load to a large extent and all the subsequent measures can effectively minimize overheating. If this possibility is not used, a real improvement will be very difficult or even impossible to attain.

Another common simple measure, which is not considered in this paper, is to block excessive solar gains by means of permanent or temporary window shading [1,5]. Doubts about this issue concern the simultaneous reduction of daylight [5]. The issues of high demand on lighting in office spaces and required by the European directive evaluation of primary energy use also demand a lot of attention. On the other hand, the new shading systems combined with PV arrays or thermal collectors may produce electricity [5], thus decreasing demand on primary energy.

A special feature of office buildings is the typically large thermal load resulting from the energy gains from people, technical equipment, and solar gains. In the simulated building, this was the main cause of the particularly uncomfortable thermal conditions for users, lasting up to $19 \%$ of entire summer period. All the possibilities to restrain these gains should be seriously considered at the initial design stage in order to reduce the total energy consumption and the thermal load of the interior. In this article, the author has tried to concentrate on a specific question regarding the influence of the external wall structure on the intensity of interior overheating. Some aspects of this problem relating to, for example, the thermal inertia of building components or the distribution of massive layers, are widely analyzed in the world. Several articles on this topic were cited in introduction. The authors of these articles in general confirmed the suitability of the high inertia to reduce the heating and cooling demand, but at the same time, they significantly differ in the amount of this potential reduction.

The relationship between overheating and the thermal insulation layer is rarely discussed. It may be presumed that the thickness of thermal insulation is not usually considered as a matter of discussion because of dominating winter heating needs. However, in the reviewed literature, one can find strong negative opinions about the adverse effect of thick thermal insulation layers in the context of space overheating. The strongest opinions on this subject can be read in the previously quoted works of Stazi [11] and also in works of Hoff et al. [7], Kolaitis et al. [20] and Goia et al. [21]. By contrast, Fanga [17], Yuan [18], and Al-Sanea [19] confirm the positive influence of thermal insulation on overheating reduction.

According to Serghides et al. [8], high thermal resistance combined with thermal capacity seems to be the right measures to achieve this goal. Hudobivnik et al. [33] observed that efficient thermal insulation prevents excessive energy conduction into the space on very hot days and massive layer acts as a heat sink thermally coupled with the space.

In his field measurements, Kisilewicz [22] proved that during hot and sunny periods of the year, south opaque walls should function as an efficient heat accumulator rather than a heat discharging element in the Central European climate. The experimental research described by Kisilewicz [22] 
may be treated as an experimental starting point for the simulation analysis contained in this article. The external reference wall structure that was adopted in simulation model is the same as in the monitored office building.

In previously reported experimental research it was shown that in case of the heavily glazed office space (Figure 8) more energy was delivered on a hot summer day by the southern wall to building interior than was dissipated to the external environment during one hot summer week. During this week, the outside air temperature dropped to around $15{ }^{\circ} \mathrm{C}$ at night, while during the day, it increased to even up to $36^{\circ} \mathrm{C}$. Theoretically, these environmental conditions were excellent for the night time discharge of collected energy. Heat flux intensity was measured on the internal surface of the south-oriented double-layer wall (outside the transparent insulation area). Measurements were performed whilst taking into account the direction of the instantaneous heat flow. A positive number meant that the heat flowed into the wall while a negative number refers to heat delivered to the interior. The weekly heat flow balance at the internal face of the tested wall was negative and equal to $-193.5 \mathrm{Wh} / \mathrm{m}^{2}$, while the sum of the absolute values of heat flow was three times higher at $586.4 \mathrm{Wh} / \mathrm{m}^{2}$. The sum of the absolute values was intended as a measure of the total heat exchange at the internal face [22]. The measurements conducted in the examined office space proved that insulation did not evidently contribute evidently to overheating during the most demanding summer conditions. The energy balance of the wall for the whole period was positive, i.e., losses were higher than gains. This means that heat flow to the external environment obviously dominates even for the whole summer period. However, the heat balance of the selected hot week significantly differs from the simple stationary heat exchange scenario in which heat flow is a function of the temporary temperature difference of both environments.

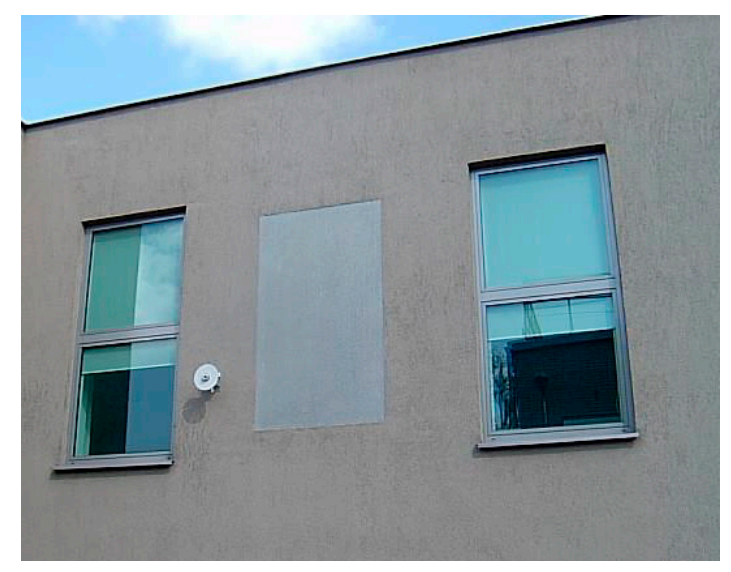

Figure 8. South-oriented double-layer wall in the tested office space [22].

The conclusion from this experiment is pretty close to the results of the simulations presented in this paper. A comparison of the conditions in the reference building and in a theoretical building without any external insulation shows only a small ( $2 \%$ of the total time) difference in the duration of the overheating period (Table 4). When another extreme case was considered-thermal insulation with a thickness of $30 \mathrm{~cm}$-overheating duration increased when compared to the standard building by $1 \%$ of the total simulation period $(31 \mathrm{~h})$.

The practical conclusion, formulated on the basis of experimental tests and simulation calculations, is that the effects of thermal insulation thickness on overheating are of limited importance. If one accepts the obvious fact that some thermal insulation of external walls is necessary in central European climate, it should be stated that its further thickening has practically insignificant influence on the overheating period. This conclusion is against the opinions expressed by Hoof et al. [7], Stazi [11], Kolaitis et al. [20] and Goia et al. [21]. 
Table 4. Summary of the obtained results, discomfort duration vs. external wall structure, and ventilation intensity.

\begin{tabular}{clcc}
\hline \multicolumn{3}{c}{ Discomfort Duration (h) } \\
\hline \multicolumn{1}{c}{ Variant description } & \multicolumn{2}{c}{ Acceptance range } \\
& & $90 \%$ & $80 \%$ \\
1 & ceramic blocs & 620 & 539 \\
2 & ceramic blocs $+10 \mathrm{~cm}$ of EPS & 699 & 620 \\
3 & ceramic blocs $+30 \mathrm{~cm}$ of EPS & 730 & 674 \\
4 & ceramic blocs $+10 \mathrm{~cm}$ of EPS + night cooling & 480 & 332 \\
5 & reinforced concrete $+10 \mathrm{~cm}$ of EPS + night cooling & 436 & 305 \\
6 & reinforced concrete $+30 \mathrm{~cm}$ of EPS + night cooling & 442 & 295 \\
\hline
\end{tabular}

The second simple and commonly applied measure of overheating protection is night cooling of the space by means of intensive, natural or forced, air change. A review of publications devoted to this subject would be very extensive; in this paper, only a few of the newest publications which refer directly to the raised aspects are mentioned. In the simulated building zone, ventilation intensity was assumed to be constant $(5 \mathrm{ach} / \mathrm{h}$ ) all day long, but it was additionally controlled by the requirement of minimum acceptable internal air temperature. Due to night ventilation, overheating duration decreased significantly to $13 \%$ (90\% acceptance range) and $9 \%$ ( $80 \%$ acceptance range) of the total summer period. In any office building, even very intensive night ventilation procedures can be easily implemented. The imposed subjective condition of minimum air temperature not lower than 20 degrees Celsius certainly limited the positive effects of night cooling; thus, further reduction of overheating may be also available. Any further increase of ventilation intensity is, according to information provided in the literature [2], rather ineffective.

It was expected that the effectiveness of night cooling would be directly dependent on the accumulation properties of the building structure [10]. The change of the structural material of the external wall from ceramic blocks to reinforced concrete provides only a small improvement of the interior conditions; the overheating duration was reduced to $12 \%$ of the total time in the case of the higher acceptance range and to $8 \%$ in the case of the lower acceptance range. Such a limited improvement of the conditions does not justify any material modification for this reason alone. Change of the dynamic characteristics of the wall, as a result of the replacement of the structural layer of the wall, was very significant. The dynamic heat capacity has been increased by 3.6 times, up to a value of $235.53 \mathrm{~kJ} / \mathrm{m}^{2} \mathrm{~K}$, and yet the reduction of the thermal overload of the interior was limited. Aste et al. [13] evaluated that cooling demand may be reduced by a maximum of $20 \%$ in the case of a high inertia building (the authors did not directly consider overheating intensity or its duration). It should be noted, however, that in analyzed building the external walls are only a fraction of the entire building structure and its thermal capacity and hence their limited influence on indoor conditions. Good possibilities of controlling the thermal capacity of the building structure provide easily accessible and more frequently used phase-changing materials. Use of PCM dispersed in thermal insulation was mentioned earlier, but a more common approach is to apply internal cladding containing these materials [6]. Aste et al. [13] also emphasized that the role of the thermal inertia becomes more important when it is coupled with other energy savings measures. This statement is in strong agreement with the combination of efficient thermal mass and night cooling suggested above.

\section{Conclusions}

Low energy buildings require a new approach to the design process. Unfortunately, due to lack of experience, modern buildings are often designed in the traditional linear way and the most important design decisions are based on intuition, current trends or even popular opinions. The conscious and rational design of low-energy buildings requires linking basic architectural and structural decisions with their effects. Such a relationship should already be observed at the stage of preliminary design concept when building orientation, technology, thermal zoning, and thermal insulation is considered. 
Improper design decisions often result in increased energy consumption and thermal discomfort. For the user, the latter aspect may be particularly troublesome and difficult to accept.

A passive cooling strategy enables avoiding, or at least significantly decreasing, the energy demand-as suggested in the European Energy Performance Directive. At the same time, the simple passive measures allow the maintaining of acceptable indoor environment quality.

Presented in the context of space overheating, a specific structure of the office energy balance leads to the evident conclusion that the first action should be oriented towards the power reduction of technical equipment that dissipates heat and on an easily available and efficient lighting system. The economic efficiency of such actions must be considered not only in respect of the direct reduction of demand on electricity but also as a possible reduction of the cooling energy demand. When designing office space, it is necessary to consider the possibility of placing at least part of the auxiliary equipment in separate technical rooms or less loaded thermal zones and to pay attention to the energy efficiency of office equipment and lighting.

In this article, particular attention has been paid to passive measures of protection against overheating. Detailed conclusions from the conducted analysis are as follows.

1. Building designers have a number of passive solutions against building overheating at their disposal, and all the possibilities should be used, or at least considered at the initial stage of building design. Usually, passive solutions do not entail significant increase in investment costs or expensive maintenance.

2. The structure and thermal properties of external walls affect the values and variability of the conditions inside the building. This applies to both the required heating and cooling energy. While the relationship between thermal insulation and heating is well-known, the effect of thermal insulation on overheating is not so obvious. In this situation, there may be a significant and difficult to resolve contradiction in the pursuit of the minimization of the energy demand.

3. The duration of overheating in an intensively used office space without wall insulation and window shading is approximately 26 or 23 days, depending upon the expected acceptance range.

4. The use of a thermal insulation layer $(10 \mathrm{~cm})$ in a standard wall extends the overheating period by $\sim 12 \%$ to $15 \%$ compared to the variant without insulation. However, it is more important to assess in the next step the impact of very thick layers of thermal insulation. Thermal insulation thickened up to $30 \mathrm{~cm}$ extends the overheating period by $4 \%$ to $9 \%$, which equates to an extra 1.3 to 2.2 days.

5. The well-known strategy of the night cooling of buildings has been of great importance for thermal comfort. In the analyzed room, it enabled a $31 \%-46 \%$ reduction of the overheating period. The positive effect of high inertia on overheating is widely accepted, but quantitative assessments are very different. In the simulated facility, the introduction of a reinforced concrete structure enabled the further reduction of overheating by $8 \%$ to $9 \%$.

6. Increasing the insulation thickness up to $30 \mathrm{~cm}$ in a night-cooled concrete building has practically no effect on the overheating period; no 'thermos effect' is observed in this case.

Thermal insulation of external walls and a low U-value are not crucial factors with regard to overheating risk. Thermal insulation of a standard thickness is responsible for a small increase in overheating duration, but its further thickening, even up to $30 \mathrm{~cm}$, has virtually no effect on indoor conditions.

Increased night ventilation during the hot weather period is a simple and effective way to discharge the building and limit its overheating. The night cooling potential depends, of course, not only on the external air temperature, but also on the building thermal capacity and the lowest acceptable internal temperature. The correct choice of construction technology should take into account-at the stage of non-linear building design-its ability to accumulate heat and cold. The complex dynamic heat transfer characteristics of the external shell of the building must be calculated and considered when looking for optimal solutions. It is still not commonly understood 
why a massive wall layer, which is unimportant when only the U-value is considered, becomes critical in dynamic conditions.

In light of the obtained results, it should be concluded that there is no contradiction between good insulation and comfort during the summer. There is also no contradiction between the reduction of energy use and human comfort. Low energy buildings with thick insulation layers and a tight external envelope, when rationally designed and adequately operated, will assure thermal comfort for inhabitants. Such a solution brings contemporary construction closer to the idea of sustainable development.

The basic analysis performed in the article involved many limitations and still leave many detailed questions to be resolved in the future. An important issue is, for example, the dependence of the formulated conclusions on the space size, its geometry, or the local climate. This article has focused on the wall with a southern orientation; a similar analysis should be made for other orientations. With this in mind, the problem of using external components with different properties, depending on the orientation of the partition, may also be raised. All methods of overheating prevention should be used in design practice and building maintenance, but not all of them are equally important. Additionally, synergy or elimination between different activities can be expected, and these interrelationships should be further investigated.

Funding: This work has been conducted in the framework of the research grant of Cracow University of Technology DS/L-1/154, and financed by the Polish Ministry of Science and Higher Education.

Conflicts of Interest: The author declares no conflicts of interest.

\section{References}

1. Ibrahim, A.; Pelsmakers, S.L.J. Low-energy housing retrofit in North England: Overheating risks and possible mitigation strategies. Build. Serv. Eng. Res. Technol. 2018, 39, 161-172. [CrossRef]

2. Kisilewicz, T. Passive control of indoor climate conditions in low energy buildings. Energy Procedia 2015, 78, 49-54. [CrossRef]

3. Kisilewicz, T. Overheating-An unexpected side-effect of decreased heating demand. In Proceedings of the 2nd Central European Symposium on Building Physics, Vienna, Austria, 10-12 September 2013; pp. 125-130.

4. Kisilewicz, T. Computer Simulation in Solar Architecture Design. Architect. Eng. Manag. Des. 2007, 3, 106-123. [CrossRef]

5. Nowak, H.; Nowak, Ł.; Śliwińska, E. The impact of different solar passive systems on energy saving in public buildings and occupants' thermal and visual comfort. J. Build. Phys. 2016, 40, 177-197. [CrossRef]

6. Pacheco-Torgal, F.; Labrincha, J.; Cabeza, L.; Granqvist, C.G. (Eds.) Eco-Efficient Materials for Mitigating Building Cooling Needs: Design, Properties and Applications, 1st ed.; Woodhead Publishing Series in Civil and Structural Engineering, Number 56; Woodhead Publishing: Cambridge, UK, 2015; p. 533, ISBN 9781782423805.

7. Hooff, T.; Blocken, B.; Hensen, J.L.M.; Timmermans, H.J.P. On the predicted effectiveness of climate adaptation measures for residential buildings. Build. Environ. 2014, 82, 300-316. [CrossRef]

8. Serghides, D.K.; Georgakis, C.G. The building envelope of Mediterranean houses: Optimization of mass and insulation. J. Build. Phys. 2012, 36, 83-98. [CrossRef]

9. D'Orazio, M.; Di Perna, C.; Di Giuseppe, E. A field study of thermal inertia of roofs and its influence on indoor comfort. J. Build. Phys. 2014, 38, 50-65. [CrossRef]

10. Evola, G.; Marletta, L.; Costanzo, V.; Caruso, G. Different Strategies for Improving Summer Thermal Comfort in Heavyweight Traditional Buildings. Energy Procedia 2015, 78, 3228-3233. [CrossRef]

11. Stazi, F. Thermal Inertia in Energy Efficient Building Envelopes; Butterworth-Heinemann: Oxford, UK, 2015.

12. Kossecka, E.; Kośny, J. Influence of insulation configuration on heating and cooling loads in a continuously used building. Energy Build. 2002, 34, 321-331. [CrossRef]

13. Aste, N.; Angelotti, A.; Buzzetti, M. The influence of the external walls thermal inertia on the energy performance of well insulated buildings. Energy Build. 2009, 41, 1181-1187. [CrossRef]

14. Kośny, J.; Fallahi, A.; Shukla, N.; Kossecka, E.; Ahbari, R. Thermal load mitigation and passive cooling in residential attics containing PCM-enhanced insulations. Sol. Energy 2014, 108, 164-177. [CrossRef] 
15. Tuohy, P.; McElroy, L.; Johnstone, C. Thermal mass, insulation and ventilation in sustainable housing-An investigation across climate and occupancy. In Proceedings of the Ninth International IBPSA Conference, Montréal, QC, Canada, 15-18 August 2005.

16. Verbeke, S.; Audenaert, A. Thermal inertia in buildings: A review of impacts across climate and building use. Renew. Sustain. Energy Rev. 2018, 82, 2300-2318. [CrossRef]

17. Fanga, Z.; Lia, N.; Lia, B.; Luod, G.; Huanga, Y. The effect of building envelope insulation on cooling energy consumption in summer. Energy Build. 2014, 77, 197-205. [CrossRef]

18. Yuan, L.; Kang, Y.; Wang, S.; Zhong, K. Effects of thermal insulation characteristics on energy consumption of buildings with intermittently operated air-conditioning systems under real time varying climate conditions. Energy Build. 2017, 155, 559-570. [CrossRef]

19. Al-Sanea, S.A.; Zedan, M.F. Improving thermal performance of building walls by optimizing insulation layer distribution and thickness for same thermal mass. Appl. Energy 2011, 88, 3113-3124. [CrossRef]

20. Kolaitis, D.I.; Malliotakis, E.; Kontogeorgos, D.A.; Mandilaras, J.; Katsourinis, D.I.; Founti, M.A. Comparative assessment of internal and external thermal insulationsystems for energy efficient retrofitting of residential buildings. Energy Build. 2013, 64, 123-131. [CrossRef]

21. Goia, F.; Time, B.; Gustavsen, A. Impact of opaque building envelope configuration on the heating and cooling energy need of a single family house in cold climates. Energy Procedia 2015, 78, 2626-2631. [CrossRef]

22. Kisilewicz, T. Thermal insulation versus overheating-Monitoring results. Conf. Ser. Mater. Sci. Eng 2018, 415, 012033. [CrossRef]

23. Thermal Performance of Building Components_Dynamic Thermal Characteristics-Calculation Methods; EN ISO 13786:2017; International Organization for Standardization: Geneva, Switzerland, 2017.

24. Gori, P.; Guattari, G.; Evangelisti, L.; Asdrubali, F. Design criteria for improving insulation effectiveness of multilayer walls. Int. J. Heat Mass Transf. 2016, 103, 349-359. [CrossRef]

25. Di Perna, C.; Stazi, F.; Ursini Casalena, A.; D'Orazio, M. Influence of the internal inertia of the building envelope on summertime comfort in buildings with high internal heat loads. Energy Build. 2011, 43, $200-206$. [CrossRef]

26. Henninger, R.H.; Witte, M.J. EnergyPlus Testing with Building Thermal Envelope and Fabric Load Tests from ANSI/ASHRAE Standard 140-2011. Prepared for U.S. Department of Energy Energy Efficiency and Renewable Energy Office of Building Technologies, Washington, D.C.; GARDA Analytics: Arlington Heights, IL, USA, 2014; pp. 1-132.

27. Indoor Environmental Input Parameters for Design and Assessment of Energy Performance of Buildings Addressing Indoor Air Quality, Thermal Environment, Lighting and Acoustics; EN ISO 15251:2012; The Polish Committee for Standardization (Polski Komitet Normalizacyjny—PKN): Warszawa, Poland, 2012.

28. Schweiker, M.; Brasche, S.; Bischof, W.; Hawighorst, M.; Wagner, A. Explaining the individual process leading to adaptive comfort: Exploring physiological, behavioral and psychological reactions to thermal stimuli. J. Build. Phys. 2013, 36, 438-463. [CrossRef]

29. Pfafferott, J.Ü.; Herkel, S.; Kalz, D.E.; Zeuschner, A. Comparison of low-energy office buildings in summer thermal comfort using different criteria. Energy Build. 2007, 39, 750-757. [CrossRef]

30. D'Ambrosio Alfano, F.R.; Olesen, B.W.; Palella, B.I.; Riccio, G. Thermal comfort: Design and assessment for energy saving. Energy Build. 2014, 81, 326-336.

31. Psomas, T.; Heiselberg, P.; Duer, K.; Andersen, M.M. Comparison and statistical analysis of long-term overheating indices applied on energy renovated dwellings in temperate climates. Indoor Built Environ. 2018, 27, 423-435. [CrossRef]

32. Alonso, M.J.; Mathisen, H.M.; Collins, R. Ventilative cooling as a solution for highly insulated buildings in cold climate. Energy Procedia 2015, 78, 3013-3018. [CrossRef]

33. Hudobivnik, B.; Pajek, L.; Kunič, R.; Košir, M. FEM thermal performance analysis of multi-layer external walls during typical summer conditions considering high intensity passive cooling. Appl. Energy 2016, 178, 363-375. [CrossRef]

(C) 2019 by the author. Licensee MDPI, Basel, Switzerland. This article is an open access article distributed under the terms and conditions of the Creative Commons Attribution (CC BY) license (http:/ / creativecommons.org/licenses/by/4.0/). 